\title{
SCHUMANN, Jutta, Die andere Sonne. Kaiserbild und Medienstrategien im Zeitalter Leopolds I.
}

\section{Claire Gantet}

\section{OpenEdition}

Journals

Édition électronique

URL : http://journals.openedition.org/ifha/1042

DOI : $10.4000 /$ ifha. 1042

ISSN : 2198-8943

Éditeur

IFRA - Institut franco-allemand (sciences historiques et sociales)

Référence électronique

Claire Gantet, «SCHUMANN, Jutta, Die andere Sonne. Kaiserbild und Medienstrategien im Zeitalter Leopolds I. », Revue de l'IFHA [En ligne], Date de recension, mis en ligne le 01 janvier 2004, consulté le 22 septembre 2020. URL : http://journals.openedition.org/ifha/1042 ; DOI : https://doi.org/10.4000/ ifha. 1042

Ce document a été généré automatiquement le 22 septembre 2020.

(C)IFHA 


\title{
SCHUMANN, Jutta, Die andere Sonne. Kaiserbild und Medienstrategien im Zeitalter Leopolds I.
}

\author{
Claire Gantet
}

1 Issu d'une thèse soutenue à Augsbourg en 2000, ce livre étudie l'image de Léopold - un empereur ignoré, voire dénigré par l'historiographie nationaliste du XIXe et du début du XXe s. - dans les divers médias contemporains : feuilles volantes, gravures, journaux, fêtes officielles, art et architecture, historiographie, théâtre, médailles, sermons, thèses. Après un chapitre introductif de terminologie (où sont définis avec clarté les termes Öffentlichkeit, Medien et Propaganda), l'auteur passe en revue les divers événements du règne et leur présentation par les divers médias, depuis l'élection de l'empereur en 1658 jusqu'à la guerre de Succession d'Espagne. La masse des documents consultés par J.S. est impressionnante : 800 feuilles volantes, 110 gravures, 75 chansons, 10 tomes du Theatrum Europaeum édités par Merian, etc. Elle s'attache aussi à inscrire ces documents dans le circuit de leur production et de leur distribution. Elle souligne le bilan globalement positif du règne : Léopold a su surmonter les tensions issues de la guerre de Trente Ans et animer une image globalement acceptée, bien que fondée sur une démonstration de piété catholique. J.S. montre aussi que, même dans le secteur des journaux, où elle constate un engagement croissant du gouvernement, les médias, dans l'ensemble, à l'exception des fêtes et de l'historiographie, ne sont pas contrôlés par Vienne. Ce livre repose donc sur une étude très fouillée. Quelques éléments atténuent ce bilan très positif. Bien qu'intitulé l'« autre soleil », le livre ne mène pas une étude réellement comparative entre l'image de Louis XIV et celle de Léopold. On ne peut d'abord qu'être étonné par le contraste entre l'absence d'instance de contrôle de l'opinion du public dans le Saint-Empire (les médailles par exemple sont guidées par des considérations avant tout économiques) et le fameux " cabinet noir " ou le rôle des lieutenants de police, des divers ministres et des prête-noms en France. Quelles en sont les raisons ? L'auteur, ensuite, ne différencie pas les médias selon la confession de leur auteur ; elle aurait pu connaître les travaux de Jean-Marie Valentin sur le théâtre des jésuites et plus encore la thèse de Maria Goloubeva sur l'image de 
Léopold dans les arts de cour à Vienne. Elle n'analyse pas du tout, enfin, le pouvoir mis en scène par ces textes. Elle ne consacre pas une ligne, par exemple, au thème de la raison d'État, à l'absolutisme (et à ses nouvelles interprétations), aux genres littéraires auxquels les textes puisent (parfois écrits sous forme de songe), et au thème du pouvoir. La connaissance des travaux de Louis Marin lui aurait permis d'effectuer un saut qualitatif de taille dans l'interprétation du matériel rassemblé. Ce livre est toutefois un jalon important dans l'actuelle réévaluation du XVIIe s.

2 Claire GANTET (Université Paris I / Max-Planck-Institut

3 für Wissenschaftsgeschichte, Berlin) 